\title{
A Comparative Study between Different Therapeutic Modalities for the Management of Patients with Graves' Disease
}

\author{
Elshorbagy EA, Najlaa Ali Khalifa, Mohamed El Hamali Mohamed Zawia*, Mohamed M. Awad \\ Department of Internal Medicine, Faculty of Medicine, Zagazig University, Egypt \\ *Corresponding Author: Mohamed El Hamali Mohamed Zawia, Mobil: (00218)927520875, \\ E-mail: mahamedzawia@gmail.com
}

\begin{abstract}
Background: The most prevalent cause of thyrotoxicosis is Graves' disease. It can be treated with antithyroid medications (ATD), radioactive iodine (RAI), or a near-total thyroidectomy, among other options.

Objective: The aim of the current study was to compare between different therapeutic modalities for the management of patients with Graves disease.

Patients and Methods: This Prospective Cohort study included a total of 48 patients with Graves' disease, treated and followed up at the Endocrinology Unit, Department of Internal Medicine, Faculty of Medicine, Zagazig University and both Outpatient Clinics and Medical Departments of Tripoli Medical Center. All patients were subjected to clinical examination of thyroid gland, thyroid function tests (FT3, FT4, TSH) and measurement of thyroid stimulating hormone receptor autoantibodies (TRAb) level.

Results: There was statistically significant difference of mean TRAb value before and after treatment in three therapeutic modalities. On other hand, there was marked decreased mean TRAb after treatment with different modalities; difference statistically significant $\mathrm{p}<0.05$. The decline percent of TRAb values were $97.41 \%, 93.48 \%, 82.01 \%$ by surgical modalities, GI modalities and GII modalities respectively.

Conclusion: It could be concluded that surgery appear to be the useful therapeutic modality associated with significant decrease in TRAb level and inducing remission of graves' disease.

Keywords: Graves' disease, TRAb, Antithyroid drugs, Radioiodin therapy.
\end{abstract}

\section{INTRODUCTION}

Graves' disease is an autoimmune disease characterized by the activation of thyroid-stimulating hormone (TSH) receptor antibodies (TRAb) and hypersecretion of thyroid hormone ${ }^{(\mathbf{1})}$. It is treated using three different modalities: antithyroid drugs, radioactive iodine (RAI) ablation, or surgery ${ }^{(2)}$.

TRAb is a useful diagnostic tool for diagnosis of Graves' disease. The prevalence of TRAb in hyperthyroid and Graves disease is $70-100 \%{ }^{(3,4)}$.

The fate of TRAb during and following Graves' disease (GD) treatment is an important aspect of the pathophysiology of GD and has been examined previously ${ }^{(5)}$. Most studies showed a decline in TRAb levels over months to years ${ }^{(6)}$. The rate of decline depended on treatment modality and initial TRAb levels ${ }^{(5)}$.

The aim of the present study was to comparative study between different Therapeutic Modalities for the management of patients with Graves disease.

\section{PATIENTS AND METHODS}

This Prospective Cohort study included a total of 48 patients with Graves' disease, treated and followed up at the Endocrinology Unit, Department of Internal Medicine, Faculty of Medicine, Zagazig University and both Outpatient Clinic and Medical Departments of Tripoli Medical Center. This study was conducted between March 2020 to March 2021.

\section{Ethical Consideration:}

This study was ethically approved by Research Ethics Committee of the Faculty of Medicine, University of Zagazig. Study had been performed on research with human subjects in accordance with the Code of Ethics of the World Medical Association (Declaration Helsinki). Written informed consent of all the subjects was obtained.

Individuals aged between 37-53 years with GD. Participants were categorized into three groups; Group I: included 16 patients with GD ( 3 male \& 13 female, mean age value $44.56 \pm 4.23$ and duration of disease $2.88 \pm 1.15)$. They had received antithyroid drugs. Group II: included 16 patients ( 2 male \&14 female, mean age value $44.13 \pm 4.75$ and duration of disease $3.06 \pm 1.12$ ) with GD They had received radioiodine therapy. Group III: included 16 patients with GD (2 male \& 14 female, mean age value $46.94 \pm 4.65$ and duration of disease $3.25 \pm 1.13$ ). They were subjected to near total thyroidectomy.

Inclusion criteria included patients with Graves' disease diagnosed by Clinical, biochemical and immunological evidence, TRAb, with or without goiter. Exclusion criteria included other causes of thyrotoxicosis. 
All patients were subjected to full history taking, complete physical examination for all patients, clinical examination of thyroid gland, full ophthalmological examination to assess eye signs (e.g., lid retraction, lid lag, lack of convergence, infrequent blinking, affection of recti,....) and using Hertl's exophthalmometer to assess the severity of exophthalmos. Thyroid function tests (FT3, FT4, TSH). Measurement of TSH receptor antibody level at baseline and then three months later on to evaluate the effect of different therapeutic treatment modalities on the immunological profile of the studied groups.

Exophthalmos was estimated by measuring the degree of forward displacement of the eye. The device allows measurement of the forward distance of the lateral orbital rim to the front of the cornea. Measurement is taken from the lateral orbital rim to the corneal apex. The normal range is up to $18 \mathrm{~mm}^{(7)}$.

\section{Biochemical testing:}

Serum Free T3, Free T4, TSH and TRAb were measured. Test procedure for measurement of free $\mathrm{T} 3$ and Free T4: (Elecsys 2010 and Cobas e 2011 analyzers. Roche). Test procedure for measurement of TSH: (Modular Analytics E170, Cobas e 601 and Cobas e 602 analyzers. Roche)

Test procedure for measurement of TRAb: Serum TRAb was measured by ELIZA technique.

\section{Statistical Analysis}

The collected data were coded, processed and analyzed using the SPSS (Statistical Package for Social Sciences) version 22 for Windows ${ }^{\circledR}$ (IBM SPSS Inc, Chicago, IL, USA). Data were tested for normal distribution using the Shapiro Walk test. Qualitative data were represented as frequencies and relative percentages. Chi square test $(\chi 2)$ to calculate difference between two or more groups of qualitative variables. Quantitative data were expressed as mean \pm SD (Standard deviation). Independent samples t-test was used to compare between two independent groups of normally distributed variables (parametric data). $P$ value $<0.05$ was considered significant.

\section{RESULTS}

Table (1): Comparison between demographic characteristics of studied groups

\begin{tabular}{|c|c|c|c|c|c|}
\hline & \multicolumn{3}{|c|}{ Studied groups } & \multirow[b]{2}{*}{$\chi^{2}$} & \multirow[b]{2}{*}{$\mathbf{P}$} \\
\hline & $\begin{array}{c}\text { Group I } \\
\text { n.16 } \\
\end{array}$ & $\begin{array}{c}\text { Group II } \\
\text { n.16 } \\
\end{array}$ & $\begin{array}{c}\text { Group III } \\
\text { n.16 } \\
\end{array}$ & & \\
\hline $\begin{array}{l}\text { Age (years) } \\
\text { Mean } \pm \text { SD } \\
\text { Median(range) }\end{array}$ & $\begin{array}{c}44.56 \pm 4.23 \\
45(38-52)\end{array}$ & $\begin{array}{c}44.13 \pm 4.75 \\
44(37-52)\end{array}$ & $\begin{array}{c}46.94 \pm 4.65 \\
47(38-53)\end{array}$ & $\mathrm{F}=1.77$ & 0.182 \\
\hline $\begin{array}{l}\text { Gender } \\
\text { Females }(\%) \\
\text { Males }(\%)\end{array}$ & $\begin{array}{c}13(81.25 \%) \\
3(18.75 \%)\end{array}$ & $\begin{array}{c}14(87.5 \%) \\
2(12.5 \%)\end{array}$ & $\begin{array}{c}14(87.5 \%) \\
2(12.5 \%)\end{array}$ & 0.33 & 0.85 \\
\hline $\begin{array}{l}\text { Smoking } \\
\text { Yes }(\%) \\
\text { No }(\%)\end{array}$ & $\begin{array}{c}3(18.75 \%) \\
13(81.25 \%)\end{array}$ & $\begin{array}{c}2(12.5 \%) \\
14(87.5 \%)\end{array}$ & $\begin{array}{c}3(18.75 \%) \\
13(81.25 \%)\end{array}$ & 0.3 & 0.86 \\
\hline $\begin{array}{l}\text { Family history } \\
\text { Yes }(\%) \\
\text { No }(\%)\end{array}$ & $\begin{array}{c}12(75 \%) \\
4(25 \%)\end{array}$ & $\begin{array}{c}13(81.25 \%) \\
3(18.75 \%)\end{array}$ & $\begin{array}{c}12(75 \%) \\
4(25 \%)\end{array}$ & 0.24 & 0.89 \\
\hline $\begin{array}{l}\text { BMI }\left(\mathbf{k g} / \mathbf{m}^{2}\right) \\
\text { Mean } \pm \text { SD } \\
\text { Median }\end{array}$ & $\begin{array}{c}22.52 \pm 1.56 \\
22.67\end{array}$ & $\begin{array}{c}22.44 \pm 1.6 \\
22.81\end{array}$ & $\begin{array}{c}22.05 \pm 1.87 \\
21.74\end{array}$ & $\mathrm{~F}=.362$ & 0.699 \\
\hline
\end{tabular}

$\mathbf{F}=$ Anova test $\chi^{2}=$ Chisquare test $\mathbf{p}>0.05$ insignificant

There were no significant difference ( $p>0.05$.) as regard age, gender, smoking habit, family history and BMI among the three studied groups (Table 1). 
Table (2): Correlation between TRAb with age, clinical and laboratory findings of studied group before and after treatment.

\begin{tabular}{|l|c|c|c|c|c|c|}
\hline \multirow{2}{*}{ Variables } & \multicolumn{7}{|c|}{ TRAb before treatment } \\
\cline { 2 - 7 } & \multicolumn{2}{|c|}{ GI group } & \multicolumn{2}{c|}{ GII group } & \multicolumn{2}{c|}{ GIII group } \\
\cline { 2 - 7 } & $\mathrm{r}$ & $\mathrm{p}$ & $\mathrm{r}$ & $\mathrm{p}$ & $\mathrm{r}$ & $\mathrm{p}$ \\
\hline Age (years) & 0.086 & 0.753 & $-.387-$ & 0.138 & 0.108 & 0.691 \\
\hline BMI (kg/m ${ }^{2}$ ) & 0.124 & 0.649 & $\mathbf{. 5 4 4} *$ & $\mathbf{0 . 0 2 9}$ & -.376 & 0.151 \\
\hline Duration of graves (years) & 0.005 & 0.987 & 0.04 & 0.884 & -.084 & 0.758 \\
\hline Thyroid volume \% & 0.172 & 0.524 & 0.068 & 0.803 & 0.032 & 0.905 \\
\hline Clinical activity score & 0.487 & 0.056 & $.524 *$ & 0.037 & 0.22 & 0.412 \\
\hline Free T4 (ng/dl) & 0.085 & 0.753 & 0.259 & 0.333 & 0.034 & 0.9 \\
\hline Free T3 (ng/dl) & 0.159 & 0.556 & $-.058-$ & 0.832 & 0.118 & 0.664 \\
\hline TRAb after treatment & & & & & & \\
\hline Age per years & -.124 & 0.647 & -.015 & 0.957 & -.118 & 0.665 \\
\hline BMI & 0.49 & 0.054 & -.229 & 0.393 & 0.08 & 0.77 \\
\hline Duration of graves & -.111 & 0.683 & -.335 & 0.205 & -.018 & 0.946 \\
\hline Thyroid volume & $\mathbf{. 7 7 0} * *$ & $\mathbf{0 . 0 0 0 1}$ & 0.012 & 0.966 & 0.236 & 0.379 \\
\hline Clinical activity score & 0.348 & 0.187 & 0.176 & 0.515 & 0.26 & 0.331 \\
\hline Free T4 & 0.475 & 0.063 & 0.147 & 0.587 & -.332 & 0.209 \\
\hline Free T3 & 0.159 & 0.558 & -.124 & 0.647 & 0.263 & 0.325 \\
\hline
\end{tabular}

(r) Correlation coefficient $\mathbf{p}<0.05$ Significant

Table 2 shows that there was statistically significant positive correlation between TRAb and BMI of RAI Group (II). Illustrated that there was statistically significant positive correlation between TRAb after medical treatment and thyroid volume among medical treatment group $(\mathrm{GI})(\mathrm{p}<0.05)$.

Table (3): Comparison between TRAb (IU/L) value before and after treatment modalities of studied patients

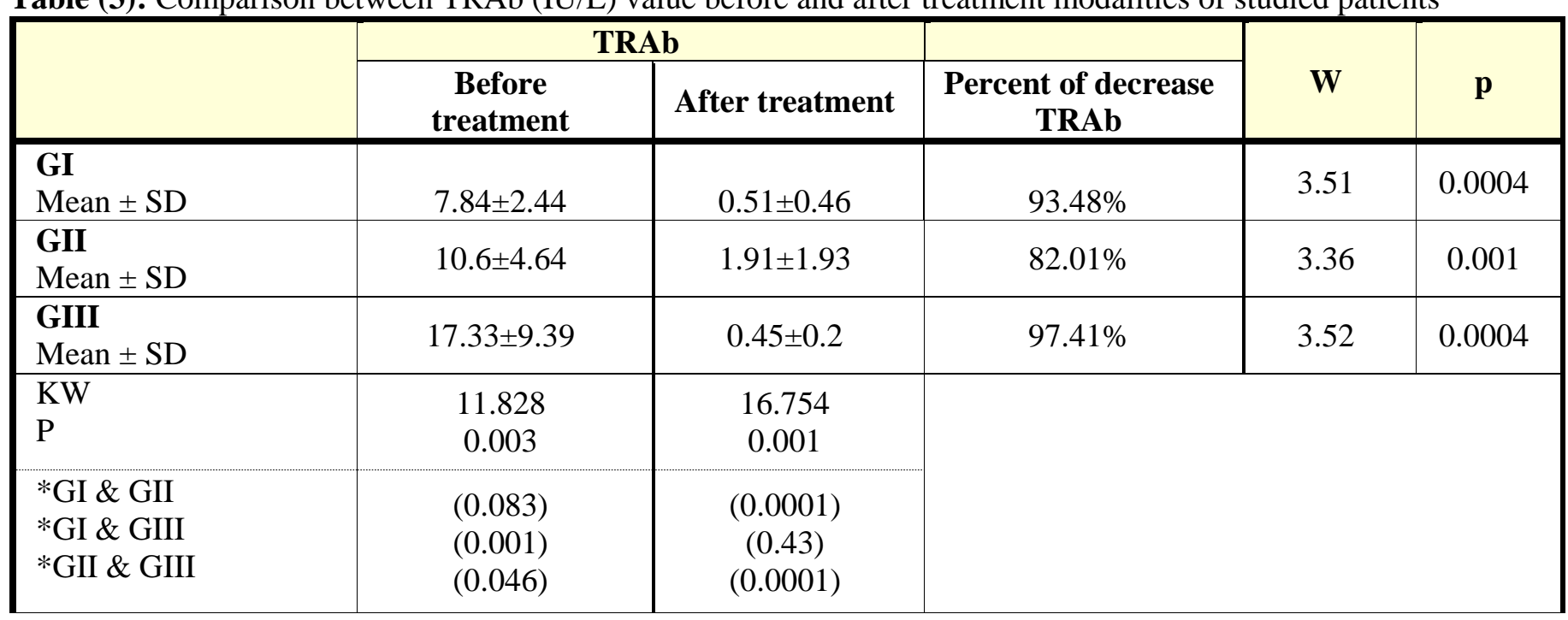

Wilcoxon sign rank test *Mann-Whitney $U$ KW $=$ Kruskal Wallis Test significant $p<0.05$ insignificant $p>0.05$

Table 3 shows that there was statistically significant $(\mathbf{p}<\mathbf{0 . 0 5})$ decrease in the mean TRAb value after treatment with three therapeutic modalities. 


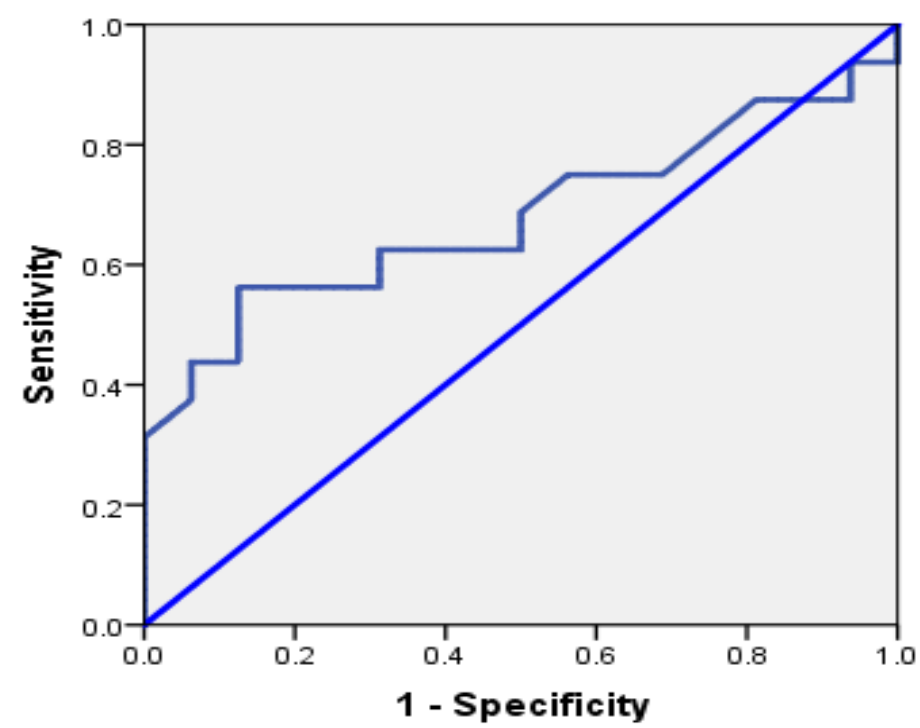

Figure (1): Performance of TRAb to discriminate GII versus GI as therapeutic modality for treatment of hyperthyroidism.

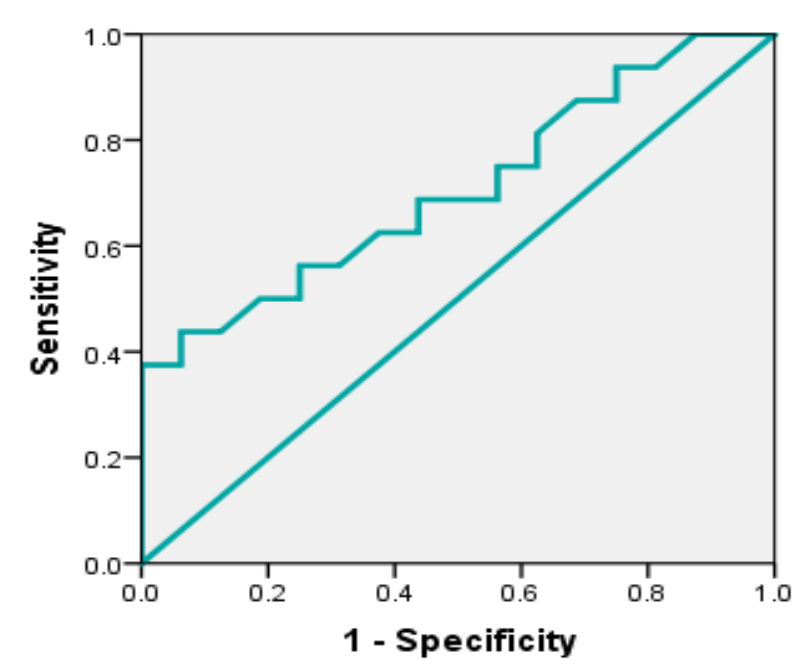

Figure (2): Performance of TRAb to discriminate GIII versus GII as therapeutic modality for treatment of hyperthyroidism.

a

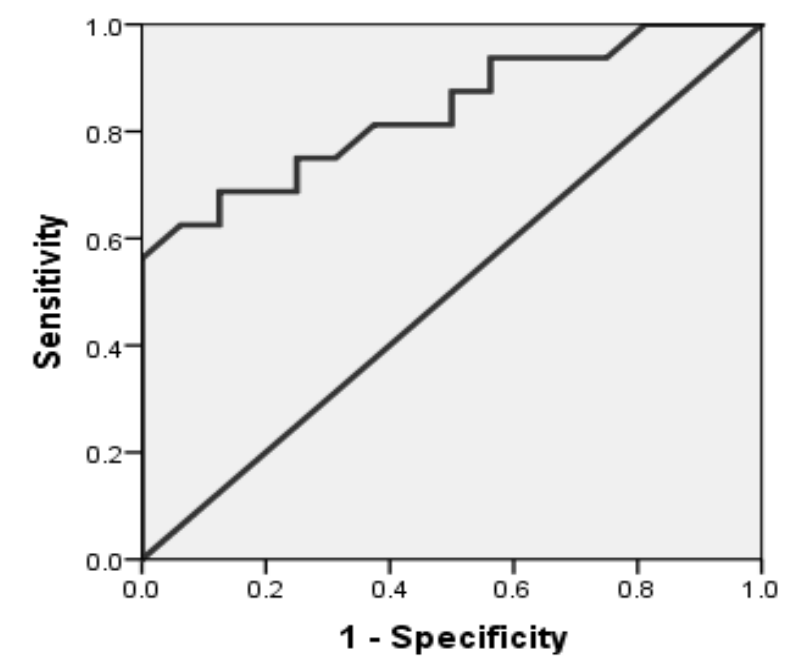

Figure (3): Performance of TRAb to discriminate surgery versus ATD as therapeutic modality for treatment of hyperthyroidism.

\section{DISCUSSION}

In line with our findings, there was a statistically insignificant difference $(\mathrm{P}>0.05)$ between the studied groups and their demographic characteristics, smoking habits, family history, and BMI. Törring et al. ${ }^{(\mathbf{8})}$ demonstrated no significant differences in mean age, number of smokers versus nonsmokers, or body weights between the studied groups.

There was no significant difference between the studied group and their clinical characteristics in this study (duration of graves, thyroid volume and clinical activity score). The majority of our patients were female. This was nearly agreed with the findings of Zarif $\boldsymbol{e} \boldsymbol{a l} .{ }^{(9)}$ who demonstrated a higher female: male ratio.

We reported a significant decrease in the mean level of TRAb after treatment with the three therapeutic modalities in this study. When comparing patients treated with surgery and antithyroid medications to those treated with radioiodine therapy, the mean decrease in TRAb level was significant. Despite having a higher level of TRAb before surgery, there was no significant difference in mean TRAb value between patients treated with surgery or antithyroid medications.

The curve of TRAb to discriminate GII as therapeutic modality for treatment of hyperthyroidism show that, Area under curve (AUC) was 0.68. So TRAb was poor marker to discriminate GII versus GI as therapeutic modality for treatment of hyperthyroidism. (Figure 1).

While, curve of TRAb to discriminate surgery as therapeutic modality versus GII for treatment of hyperthyroidism. Area under curve (AUC) was 0.707. So TRAb was fair marker to discriminate surgery versus GII as therapeutic modality for treatment of hyperthyroidism. (Figure 2). In comparison, curve of TRAb to discriminate surgery as therapeutic modality for treatment of hyperthyroidism (AUC) 0.838 . So TRAb was good marker to discriminate surgery versus ATD as therapeutic modality for treatment of hyperthyroidism (Figure 3).

In this study, there was a significant decrease in TRAb level after surgery, 97.41 percent decrease. This result was in line with a study done by Mori et al..$^{(\mathbf{1 0})}$ who stated that TRAb decline and become undetectable in most patients within 6 to 9 months after surgery. The disappearance of TRAb from the circulation in many patients points to the concept that the target organ is the primary site of autoantibody production; however, this is not always the case. Although it has not been thoroughly studied whether postoperative TRAb levels correlate with residual thyroid volume, it has been suggested that thyroidectomy may modulate the disease's immunologic activity.

Furthermore, Nalla et $\boldsymbol{a l}$. $^{(3)}$ stated that patients undergoing surgery had the greatest drop in TRAb concentration, and in most cases to undetectable levels, with a median of $11.4(6.7-2.9)$ decreasing to $0.58(0.4$ $-1.4) \mathrm{U} / \mathrm{L}$. This is consistent with several other studies 
looking into the benefits of surgery in reducing TRAb in GD patients ${ }^{(5)}$.

In the current study, we reported that treating patients with Graves' disease with ATD resulted in a 58.5 percent positive predictive value of remission when compared to those treated with radioiodine therapy. In line with this finding, Wang et $\boldsymbol{a l} .^{(\mathbf{1})}$ discovered that a good initial response to ATD in terms of TRAb level during the first year after diagnosis.

In this study, there was a 93.48 percent decrease in TRAb concentration after 3 months of follow-up after treatment with antithyroid drugs. In contrast, Laurberg et al. ${ }^{(5)}$ found that after a year of treatment with antithyroid medication and surgery, patients' TRAb levels gradually decreased to the upper level of normal.

Previous researches by Dos Santos et al. (11), Gastaldi et al. (12) hypothesized that TRAb level normalisation was a predictor of remission and that a significant drop in TRAb levels was a parameter for ATD discontinuation in $\mathrm{GD}^{(\mathbf{1 1 )}}$.

In this study, we found that the remission rate with antithyroid drugs was 93.48 percent, 82.01 percent with RAI therapy, and 97.41 percent after surgery. This is consistent with the findings of Sundaresh et al. ${ }^{(13)}$, who found that the drug remission rate was 51.7 percent, 92 percent with RAI therapy, and 100 percent with surgery.

There was a positive correlation between TRAb and Thyroid volume in this study. This finding is consistent with the findings of Sawicka and Sowiski ${ }^{(14)}$, who discovered a positive relationship between TRAb and Thyroid volume.

There was no significant correlation between age, gender, and TRAb levels at diagnosis in the ATD group in the current study. This is consistent with the findings of Wang et al. ${ }^{(\mathbf{1})}$, who found no obvious sex difference in TRAb levels at diagnosis.

There was no significant correlation between thyroid function and TRAb levels at diagnosis in the ATD group in the current study. This is consistent with the findings of Wang et al. ${ }^{(1)}$, who found no correlation between TRAb levels at diagnosis and thyroid function in the ATD group.

\section{CONCLUSION}

As a result of our findings and the findings of other studies, surgery appears to be a definitive treatment option in patients with Graves' disease. The disparity in the level of significance, on the other hand, may be explained by differences in population size and ethnicity. Thus, we recommend further studies on larger number of patients to clarify these results.

\section{REFERENCES}

1. Wang S, Wang C, Tien K et al. (2020): Thyroid stimulating hormone receptor antibodies during follow-up as remission markers in childhood-onset Graves' disease treated with antithyroid drugs. The Kaohsiung Journal of Medical Sciences, 36(4): 281-286.

2. Ross D, Burch H, Cooper D et al. (2016): American Thyroid Association guidelines for diagnosis and management of hyperthyroidism and other causes of thyrotoxicosis. Thyroid, 26(10): 1343-1421.

3. Nalla P, Young S, Sanders J et al. (2019): Thyrotrophin receptor antibody concentration and activity, several years after treatment for Graves' disease. Clinical Endocrinology, 90(2): 369-374.

4. Diana T, Olivo P, Kahaly G (2018): Thyrotropin receptor blocking antibodies. Hormone and Metabolic Research, 50(12): 853-58

5. Laurberg G. Wallin L, Abraham-Nordling M et al. (2008): TSH-receptor autoimmunity in Graves' disease after therapy with anti-thyroid drugs, surgery, or radioiodine: a 5-year prospective randomized study. European Journal of Endocrinology, 158: 69-75.

6. Yoshioka W, Miyauchi A, Ito $M$ et al. (2016): Kinetic analyses of changes in serum TSH receptor antibody values after total thyroidectomy in patients with Graves' disease. Endo J., 63:179-185.

7. Dijkstal J, Bothun E, Harrison A et al. (2012): Normal exophthalmometry measurements in United States. Ophthalmic Plastic and Reconstructive Surgery, 28(1): 54-6.

8. Törring O, Tallstedt L, Wallin G et al. (1996): Graves' hyperthyroidism: treatment with antithyroid drugs, surgery, or radioiodine - a prospective, randomized study. Thyroid Study Group. The Journal of Clinical Endocrinology \& Metabolism, 81(8): 2986-2993.

9. Zarif H, Alam S, Baashar A et al. (2020): Comparison Between the Treatment Modalities for Graves' Disease at King Abdulaziz Medical City, Jeddah. Cureus., 12(1): 6730.

10. Mori Y, Matoba N, Miura S (1992): Clinical course and thyroid stimulating hormone (TSH) receptor antibodies during surgical treatment of Graves' disease. World J Surg., 16:64752.

11. Dos Santos T, Martos-Moreno G, Muñoz-Calvo M et al. (2018): Clinical management of childhood hyperthyroidism with and without down syndrome: A longitudinal study at a single center. J Pediatr Endocrinol Metab., 31: 743-750.

12. Gastaldi R, Poggi E, Mussa A et al. (2014): Graves disease in children: Thyroid-stimulating hormone receptor antibodies as remission markers. J Pediatr., 164:1189-1194.

13. Sundaresh V, Brito J, Thapa $P$ et al. (2017): Comparative effectiveness of treatment choices for Graves' hyperthyroidism: a historical cohort study. Thyroid, 27:497-505.

14. Sawicka N, Sowiński J (2012): Correlation between thyroid volume and humoral thyroid autoimmunity after radioiodine therapy in Graves' disease. Endokrynol Pol., 63(1): 10-13. 